CLINICAL STUDY

\title{
Elevated serum levels of adiponectin in children, adolescents and young adults with type 1 diabetes and the impact of age, gender, body mass index and metabolic control: a longitudinal study
}

\author{
Angela Galler, Götz Gelbrich ${ }^{1}$, Jürgen Kratzsch ${ }^{2}$, Nicole Noack, Thomas Kapellen and Wieland Kiess \\ University Hospital for Children and Adolescents, University of Leipzig, Oststr. 21-25, D-04317 Leipzig, Germany, ${ }^{1}$ Coordination Center for Clinical Trials \\ Leipzig (KKSL), University of Leipzig, Härtelstr. 16-18, D-04107 Leipzig, Germany and ${ }^{2}$ Institute of Laboratory Medicine, University of Leipzig, Liebigstr. \\ 27a, D-04103 Leipzig, Germany \\ (Correspondence should be addressed to A Galler; Email: angela.galler@medizin.uni-leipzig.de)
}

\begin{abstract}
Objective: Adiponectin plays an important role in pathophysiology of obesity, type 2 diabetes and cardiovascular disease. The aim of this study was to determine adiponectin concentrations in children and adolescents with type 1 diabetes in a longitudinal manner and to study the impact of age, gender, body mass index (BMI) and metabolic control.

Research design and methods: In this study, 88 children and adolescents with type 1 diabetes were followed longitudinally. At baseline and during follow-up, serum levels of adiponectin were measured by enzyme-linked immunoassay and correlated with clinical data, HbAlc and lipids. Healthy children $(n=259)$ were chosen as a control group.

Results: Serum adiponectin levels were significantly higher in children with type 1 diabetes compared with healthy children $(13.1 \mathrm{vs} 9.1 \mu \mathrm{g} / \mathrm{ml}$ at baseline, $P<0.001)$. Adiponectin concentrations inversely correlated with BMI s.D.s $(P<0.001)$. No significant difference of adiponectin levels regarding gender, diabetes duration or $\mathrm{HbA1c}$ was seen. Adiponectin concentrations decreased in males with type 1 diabetes during puberty $(P=0.03)$ while there was no significant change in females. In a subgroup of patients with new onset type 1 diabetes, adiponectin concentrations were not different from adiponectin levels in control subjects but increased during follow-up $(P=0.007)$. Stepwise multiple regression analysis showed that most important predictors of adiponectin levels in type 1 diabetes at the end of the study were adiponectin concentration at baseline $(\beta=0.574, P<0.001)$ and BMI s.D.s $\left(\beta=-0.302, P=0.001, r^{2}=0.56\right)$.

Conclusions: Children and adolescents with type 1 diabetes have BMI-dependent elevated serum concentrations of adiponectin compared with healthy children.
\end{abstract}

European Journal of Endocrinology 157 481-489

\section{Introduction}

Adiponectin is a hormone produced by adipose tissue which plays an important role in the pathogenesis of metabolic and cardiovascular disease. Adiponectin is exclusively secreted by adipocytes, circulates at relatively high levels in the bloodstream and appears to play an important role in pathophysiology of obesity, type 2 diabetes and coronary artery disease (1-7). Adiponectin levels are decreased in obesity and are inversely correlated to insulin resistance $(5,8-11)$. Furthermore, low serum adiponectin levels are associated with a markedly increased risk of atherosclerotic disease like coronary artery disease $(4-8,12)$. High serum levels of adiponectin are associated with a lower risk of myocardial infarction $(5,13,14)$. Several experimental studies showed anti-inflammatory and anti-atherosclerotic effects of adiponectin. There is substantial evidence that adiponectin has protective effects as to the development of atherosclerosis $(7,15-19)$.

Cardiovascular disease is the major cause of morbidity and mortality in type 1 diabetes. There is a two- to eightfold excess risk of coronary artery disease in adults with type 1 diabetes (20-22). In type 1 diabetes, the relationship between serum adiponectin and the presence of micro- and macrovascular complications is largely unknown. Over the last years, few studies examined serum levels of adiponectin in patients with type 1 diabetes. Unexpectedly, adults with type 1 diabetes had higher serum levels of adiponectin compared with healthy adults $(12,23)$. Adiponectin serum levels were even higher in patients with microvascular complications $(12,23,24)$. The Pittsburgh Epidemiology of Diabetes Complications Study showed that adiponectin inversely predicted the incidence of coronary artery disease in adults with type 1 
diabetes (25). It needs to be clarified whether adiponectin plays an important role in the development of atherosclerosis in type 1 diabetes. Research about adiponectin is mainly focused on obesity and type 2 diabetes. The data concerning adiponectin in children and adolescents with type 1 diabetes are sparse and controversial. One study showed no differences between adiponectin levels in paediatric subjects with type 1 diabetes and those in healthy control subjects (26). Another study in children with type 1 diabetes found higher levels of adiponectin in pre-pubertal but not in pubertal children with type 1 diabetes compared with healthy children (27). No information about the influence of puberty on serum levels of adiponectin is available. Therefore, this study investigated serum concentrations of adiponectin in children and adolescents with type 1 diabetes cross-sectionally and longitudinally, and examined putative associations with age, body mass index (BMI), pubertal stage, diabetes duration and metabolic control.

\section{Subjects and methods}

\section{Subjects}

The 88 subjects with type 1 diabetes regularly attend the diabetes outpatient clinic of the University Hospital for Children and Adolescents, University of Leipzig, Germany. To be included in the study, patients had to be $<18$ years of age at the beginning of the study (baseline) and have type 1 diabetes as defined by the American Diabetes Association 1998. Clinical data like weight, height, BMI (calculated as weight $/(\text { height })^{2}$ ) and blood pressure were determined every 3 months. Pubertal Tanner staging was performed by standardized methods (Tanner stages 1-5). BMI s.D. score (BMI s.D.s) was calculated using the national reference data in Germany (28). Levels of HbA1c and albumin excretion rate in timed overnight urine collections were measured every 3 months. Microalbuminuria was defined as an albumin excretion rate of more than $20 \mu \mathrm{g} / \mathrm{min}$ in a minimum of two out of three consecutive urine specimens. Eye examination by ophthalmoscopy was performed every year in subjects over the age of 10 years independently of diabetes duration or with diabetes duration of more than 5 years according to the guidelines of International Society for Paediatric and Adolescent Diabetes. Non-fasting venous blood was collected once a year for determination of serum levels of triglycerides, cholesterol, low-density lipoprotein (LDL), high-density lipoprotein (HDL) and adiponectin. Serum was stored at $-20{ }^{\circ} \mathrm{C}$ until analysis of adiponectin concentrations. Two hundred and fiftynine healthy control subjects without diabetes and $<21$ years of age were recruited along with regular public health service examinations in pre-school and school classes from a study on anthropometric measurements
('Leipzig school children's project', (29)) and from referred children and adolescents or pre-operative visits to the paediatric outpatient clinic. To be included in the study, the control subjects had to be without any acute disease and without clinical conditions involving the endocrine-metabolic system. Investigators performing the laboratory analyses were blinded to the study hypothesis. Approval by the Ethical Committee of the Medical Faculty of the University Leipzig and informed consent from parents were obtained.

\section{Determination of HbA1c, serum cholesterol and triglycerides}

$\mathrm{HbA} 1 \mathrm{c}$ levels were determined by a commercial kit using a turbidimetric inhibition immunoassay (Tina Quant aHbA1c, Roche Diagnostics). The normal range was $4.8-6.0 \%$ with an inter-assay coefficient of variation of $8.8 \%$ for values within the normal range and of $4.1 \%$ for values above the normal range. Levels of serum cholesterol, HDLs, LDLs and triglycerides were measured using the commercially available enzymatic in vitro tests by Roche (Cholesterol CHOD-PAP, HDL-C Plus, LDL-C Plus, Triglycerides GPO-PAP, Hitachi, Roche Diagnostics).

\section{Determination of serum adiponectin}

Serum adiponectin levels were determined by a commercial kit using an enzyme-linked immunoassay (Mediagnost, Reutlingen, Germany). The sensitivity of the assay was determined to be $<0.6 \mathrm{ng} / \mathrm{ml}$. The intraassay coefficient was $<4.7 \%$ and inter-assay coefficient of variation was $<6.7 \%$.

\section{Statistical analysis}

Data are presented as means \pm s.D. Normal distribution was tested using Kolmogorov-Smirnov test. Normal distribution was observed for serum adiponectin concentrations in healthy children and adolescents but not in the children and adolescents with type 1 diabetes. After $\log _{10}(\mathrm{lg})$ transformation, normal distribution was achieved and statistical analysis was carried out using lg-transformed data. Data are presented as mean geometric adiponectin level and mean $\mathrm{lg}$ adiponectin level \pm s.D. The children and adolescents with and without type 1 diabetes were divided into different age groups at baseline and at the end of the study (3-16 and 8-20 years) and compared with their matched control group by unpaired $t$-test and ANOVA. For comparison of adiponectin concentrations in the children and adolescents with type 1 diabetes over the study period, paired $t$-test was performed. Spearman-Rho correlation analysis was used to examine associations between adiponectin levels and age, pubertal stages, BMI s.D.s, HbA1c and lipid levels. Correlation coefficients were adjusted for age and BMI. 
ANOVA was carried out for comparison of the study groups. Multiple stepwise linear regression analyses were used to determine the predictors of serum concentrations of adiponectin. Statistical significance was assumed at $P$ values of $<0.05$. Statistical parameters were calculated using SPSS program 11.0 for Windows (Chicago, IL, USA). For graphic presentation, SPSS 11.0 was used.

\section{Results}

\section{Study subjects}

Clinical characteristics of the study subjects are shown in Table 1 . The mean duration of the study was $4.8 \pm 1.2$ years (range 2.5-6.7 years). The median number of measurements of adiponectin levels per subject was 4 (range 2-7). BMI s.D.s was significantly higher at the end of the study compared with baseline $(P<0.001)$. For statistical analysis, the children and adolescents with type 1 diabetes were divided into different age groups and compared with the matched control group (age group 3-16 years at baseline and 8-20 years at the end of the study). In a subgroup of 18 children and adolescents with newly diagnosed type 1 diabetes (onset of diabetes), diabetic ketoacidosis (defined as $\mathrm{pH}$ below 7.30) was present in three children.

\section{Adiponectin serum levels in children with and without type 1 diabetes and their relationship to age and BMI}

Serum adiponectin levels were significantly higher in children and adolescents with type 1 diabetes compared with age- and gender-matched healthy children at baseline of the study (age group 3-16 years, mean geometric adiponectin $13.1 \mu \mathrm{g} / \mathrm{ml}$ in type 1 diabetes versus $9.1 \mu \mathrm{g} / \mathrm{ml}$ in control group, lg adiponectin $1.06 \pm 0.23 \mu \mathrm{g} / \mathrm{ml}$ versus $\mathrm{lg}$ adiponectin $0.90 \pm 0.23 \mu \mathrm{g} / \mathrm{ml}, \quad P<0.001, \quad \Delta \mathrm{lg}$ adiponectin $0.16 \mu \mathrm{g} / \mathrm{ml}, 95 \%$ CI $(0.11-0.23))$. Throughout the study, adiponectin concentrations were also significantly higher in subjects with type 1 diabetes compared with age- and gender-matched healthy subjects (after 2, 4 and 6 years of follow-up, $P<0.001$ ). At the end of the study, serum concentrations of adiponectin in subjects with diabetes (age group 8-20 years) were again significantly higher compared with the age- and gendermatched control group (mean geometric adiponectin $11.9 \mu \mathrm{g} / \mathrm{ml}$ in type 1 diabetes versus $8.6 \mu \mathrm{g} / \mathrm{ml}$ in control group, $\mathrm{lg}$ adiponectin $1.01 \pm 0.22 \mu \mathrm{g} / \mathrm{ml}$ versus $\mathrm{lg}$ adiponectin $0.88 \pm 0.22 \mu \mathrm{g} / \mathrm{ml}, P<0.001, \Delta 0.13 \mu \mathrm{g} / \mathrm{ml}, 95 \%$ CI (0.08-0.19)). Serum concentrations of adiponectin in children and adolescents at baseline and at the end of the study were lower in older subjects, however, this effect did not reach significance $(P=0.10)$. At baseline, a BMI S.D.s-dependent association of adiponectin levels in the group of healthy subjects $(r=-0.16, P=0.036)$ but not in

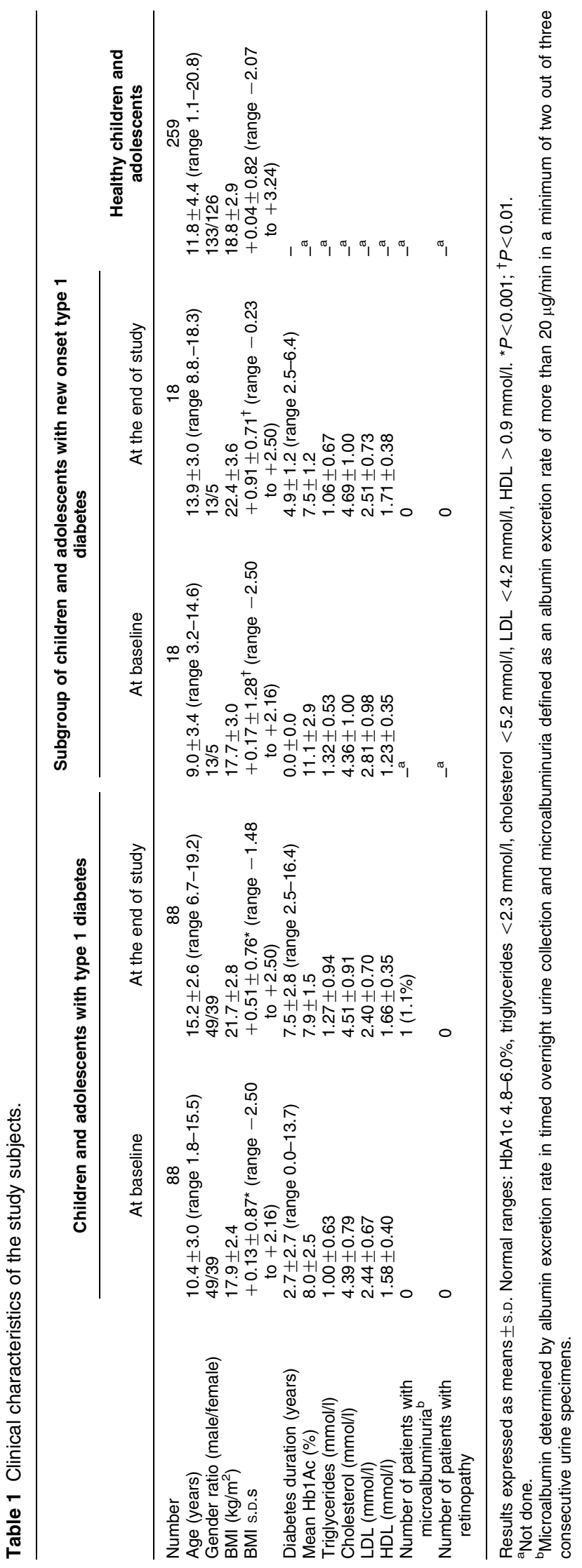

www.eje-online.org 
the age- and gender-matched group of children with type 1 diabetes $(r=0.024, P=0.82)$ was observed. At the end of the study, adiponectin levels inversely correlated with BMI S.D.s in patients with type 1 diabetes $(r=-0.29, P=0.007)$ and age- and gender-matched healthy children and adolescents $(r=-0.20, P=0.006)$ as demonstrated in Fig. 1A and B (age group 8-20 years).

\section{Relationship of adiponectin concentrations to gender and pubertal stage}

No significant difference in adiponectin concentrations between females and males with type 1 diabetes at baseline was observed $(12.5 \mu \mathrm{g} / \mathrm{ml}, \mathrm{lg}$ adiponectin $1.04 \pm 0.23 \mu \mathrm{g} / \mathrm{ml}$ in females, $13.6 \mu \mathrm{g} / \mathrm{ml}$, lg adiponectin $1.07 \pm 0.22 \mu \mathrm{g} / \mathrm{ml}$ in males, $P=0.59)$. Gender differences were not seen in the age-matched control group either. In contrast, adiponectin levels in the older age group (8-20 years) of healthy subjects were higher in females compared with males $(9.2 \pm 5.9 \mu \mathrm{g} / \mathrm{ml}$ in females versus $7.8 \pm 3.2 \mu \mathrm{g} / \mathrm{ml}$ in males, $P=0.028$ ). However, no gender difference in the age-matched group of children and adolescents with type 1 diabetes was observed $(11.8 \mu \mathrm{g} / \mathrm{ml}, \mathrm{lg}$ adiponectin $1.01 \pm 0.23 \mu \mathrm{g} / \mathrm{ml}$ in females, $11.9 \mu \mathrm{g} / \mathrm{ml}$, lg adiponectin $1.01 \pm 0.22 \mu \mathrm{g} / \mathrm{ml}$ in males, $P=0.97$ ). Therefore, serum adiponectin levels in children and adolescents before and during pubertal development were examined longitudinally in more detail. Mean adiponectin levels were calculated for pubertal stages 1-5 in each subject and depicted over pubertal development (Fig. 2). In boys with type 1 diabetes, adiponectin concentrations decreased during puberty and were significantly lower at the end of puberty compared with pre-pubertal stage $(13.2 \mu \mathrm{g} / \mathrm{ml}, \mathrm{lg}$ adiponectin $1.05 \pm 0.23 \mu \mathrm{g} / \mathrm{ml}$ in pubertal stage 1 vs $11.4 \mu \mathrm{g} / \mathrm{ml}$, lg adiponectin $1.00 \pm 0.21 \mu \mathrm{g} / \mathrm{ml}$ in pubertal stage $5, P=0.03$, Fig. 2 ). In girls with type 1 diabetes, levels of adiponectin showed no significant change during puberty (Fig. 2). Contrary to healthy children and adolescents where females have higher adiponectin levels (30), no significant difference between adiponectin concentrations in males and females with type 1 diabetes was seen at the end of puberty.

\section{Relationship of adiponectin concentrations to diabetes duration and metabolic control}

No significant correlation between serum concentrations of adiponectin and diabetes duration at baseline could be demonstrated. However, lower adiponectin levels in the subgroup of children and adolescents with newly diagnosed type 1 diabetes (onset of diabetes, $n=18$ ) compared with the subjects with a diabetes duration of at least 0.5 years were observed. Serum levels of adiponectin in children at onset of type 1 diabetes (mean geometric adiponectin $7.6 \mu \mathrm{g} / \mathrm{ml}$, lg adiponectin $0.85 \pm 0.18 \mu \mathrm{g} / \mathrm{ml}$ ) were not different from adiponectin levels in the control group (mean geometric adiponectin
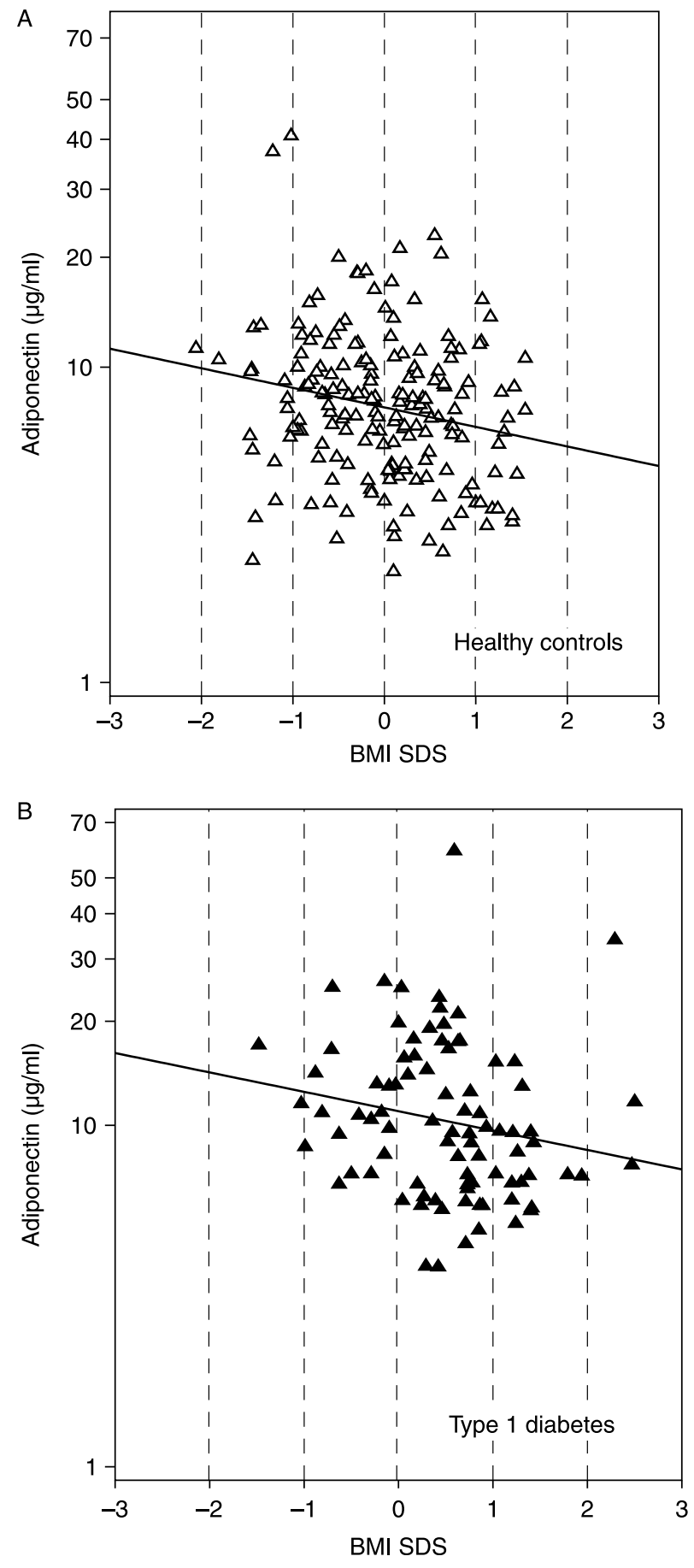

Figure 1 ( $A$ and $B$ ) Relationship between adiponectin levels and body mass index (BMI) S.D.s in healthy children and adolescents (1A) and children and adolescents with type 1 diabetes (1B) at the end of the study. Serum levels of adiponectin in children and adolescents with type 1 diabetes at the end of the study (mean age 15.2 \pm 2.6 years, mean duration of diabetes $7.5 \pm 2.8$ years, $1 \mathrm{~B}$ ) and in age- and gendermatched healthy subjects $(1 \mathrm{~A})$ correlated positively with BMI S.D.S $(r=-0.29, P=0.007$ and $r=-0.20, P=0.006)$. Serum adiponectin concentrations in children and adolescents with type 1 diabetes (1B) were significantly higher compared with age- and gender-matched healthy children and adolescents $(1 \mathrm{~A}, P<0.001)$. 


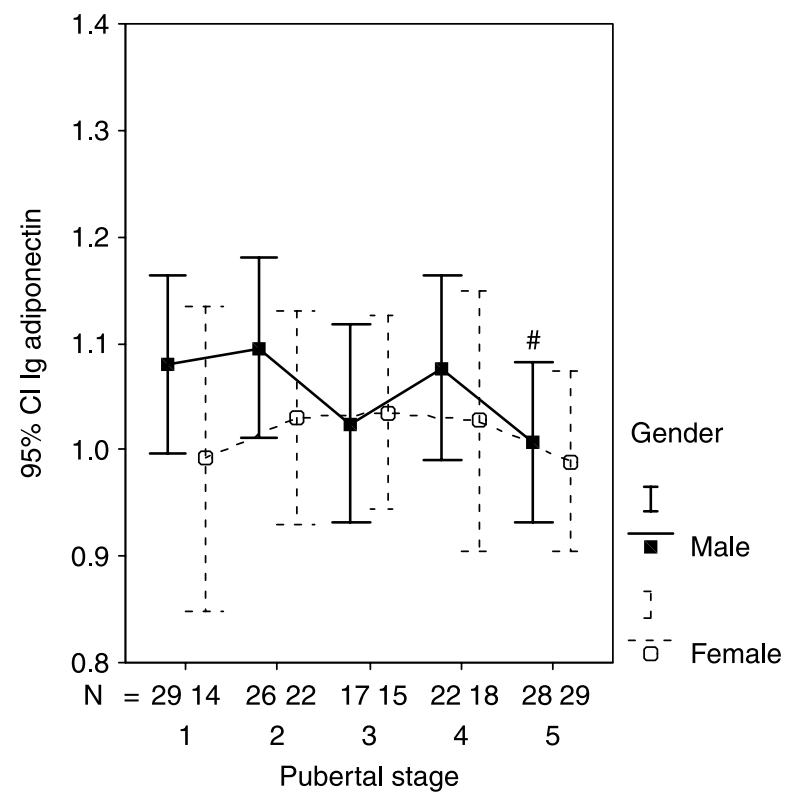

Figure 2 Serum levels of adiponectin in children and adolescents with type 1 diabetes during pubertal development. Mean adiponectin levels were calculated for pubertal stages 1-5 in each subject for males and females and depicted over pubertal development. Mean serum levels of adiponectin in males with type 1 diabetes (filled symbols, black line) decreased during puberty and were significantly lower at the end of puberty (pubertal stage 5) compared with the pre-pubertal stage (pubertal stage $1,{ }^{\#} P=0.03$ ). In females with type 1 diabetes (open symbols, dashed line), mean serum levels of adiponectin showed no significant change over puberty (data are $95 \%$ confidence interval lg adiponectin \pm s.D. for each pubertal stage). $n$, number of subjects.

$9.1 \mu \mathrm{g} / \mathrm{ml}, \mathrm{lg}$ adiponectin $0.90 \pm 0.23 \mu \mathrm{g} / \mathrm{ml}, P=0.65$, $\Delta$ lg adiponectin $0.05 \mu \mathrm{g} / \mathrm{ml}, 95 \% \mathrm{CI}(-0.08-0.18))$ but significantly lower compared with the group of children with a diabetes duration of more than 0.5 years (mean geometric adiponectin $14.4 \mu \mathrm{g} / \mathrm{ml}$, lg adiponectin $1.11 \pm 0.20 \mu \mathrm{g} / \mathrm{ml}, \quad P<0.001, \quad \Delta \quad \mathrm{lg}$ adiponectin $0.26 \mu \mathrm{g} / \mathrm{ml}, 95 \%$ CI $(0.12-0.41))$. Adiponectin levels in this subgroup of subjects with newly diagnosed diabetes were analysed longitudinally in more detail. The mean adiponectin level was estimated as $7.6 \mu \mathrm{g} / \mathrm{ml}$ at onset of diabetes ( $\mathrm{lg}$ adiponectin $0.85 \pm 0.18 \mu \mathrm{g} / \mathrm{ml}$ ) and increased significantly during follow-up (mean geometric adiponectin $12.1 \mu \mathrm{g} / \mathrm{ml}$, lg adiponectin $1.03 \pm 0.21 \mu \mathrm{g} / \mathrm{ml}$ at $0.5-2.5$ years of diabetes duration, $\Delta \mathrm{lg}$ adiponectin $0.17,95 \% \mathrm{CI}(0.05-0.28), P=0.007)$. Mean adiponectin levels were used within the time frame of 0.5-2.5 years diabetes duration after onset of diabetes. At the end of the study, serum concentrations of adiponectin increased with diabetes duration, however, this effect was not significant $(P=0.08)$.

Statistical analysis examining the relationship between metabolic control and adiponectin demonstrated no association between blood glucose levels and adiponectin levels and mean $\mathrm{HbA1c}$ and adiponectin levels (data not shown).

\section{Relationship of adiponectin concentrations to serum lipids}

For this analysis, the data of the subgroup of children with newly diagnosed diabetes were excluded. Because of the age-dependent changes in serum lipids, the study group was divided into different age groups (3-11, 11-14 and 14-20 years). Mean adiponectin and serum lipid levels were calculated in each subject for each age group and correlations are given in Table 2. No significant correlation between adiponectin concentrations and cholesterol, HDL and LDL were seen in children with type 1 diabetes in the age group up to 11 years $(n=48)$. In pubertal children with type 1 diabetes aged $11-14$ years $(n=67)$, adiponectin concentrations positively correlated with serum total cholesterol $(r=$ $0.26, P=0.03)$. Adiponectin concentrations also positively correlated with HDL levels, although statistical analysis revealed statistical significance only in trend $(r=0.23, P=0.06)$. No associations between adiponectin levels and LDL were observed. However, more detailed analysis showed different associations in females $(n=30)$ and males $(n=37)$ with type 1 diabetes. Mean serum levels of adiponectin in pubertal females correlated with HDL $(r=0.48, P=0.008)$. No significant correlation between adiponectin levels and HDL was observed in pubertal males $(r=0.04, P=0.80)$. Separate statistical analysis of the association between adiponectin concentrations and total cholesterol in females and males still showed positive correlations, although the effects did not reach significance $(r=0.33, P=0.07$ in females and $r=$ $0.22, P=0.19$ in males). Furthermore, in females with type 1 diabetes, no correlations between adiponectin levels and LDL were seen. No significant correlation between serum levels of adiponectin and LDL was observed. In the group of subjects with type 1 diabetes over the age of 14 years $(n=61)$, no significant correlations between adiponectin levels and serum lipids were observed. However, separate statistical analysis in males and females in this age group demonstrated significant correlations between adiponectin levels and cholesterol $(r=0.42, P=0.02)$ and between adiponectin levels and LDL $(r=0.40, P=0.03)$ in males, while there were no significant correlations in females.

\section{Stepwise multiple regression analysis of adi- ponectin concentrations on clinical and meta- bolic parameters}

Serum adiponectin concentrations at the end of the study significantly correlated with adiponectin levels at baseline in children and adolescents with type 1 diabetes $(r=0.61$, $P<0.001)$. Stepwise multiple regression analysis including age, gender, pubertal stage, BMI s.D.s, diabetes duration, adiponectin level at baseline, mean HbA1c and serum lipids revealed that adiponectin levels at baseline $(\beta=0.574, P<0.001)$ and BMI s.D.s $(\beta=-0.302$, $\left.P=0.001, r^{2}=0.56\right)$ determined adiponectin levels at 


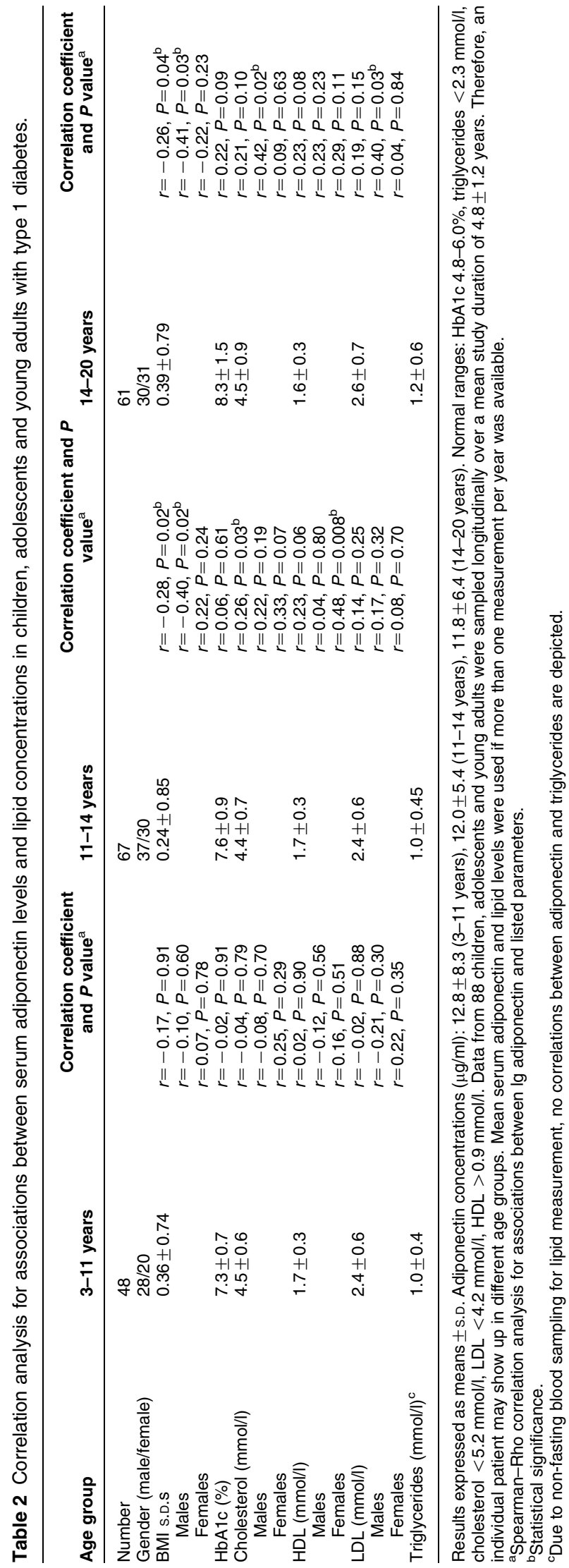

the end of the study. The most important predictor of adiponectin levels in children and adolescents with type 1 diabetes at the end of the study was adiponectin concentration at baseline.

\section{Discussion}

This study has demonstrated, as have other studies in adults with type 1 diabetes $(12,23-25)$, that serum concentrations of adiponectin are elevated in children and adolescents with type 1 diabetes. In contrast to adults, studies in children and adolescents with type 1 diabetes show controversial results $(26,27)$. Celi et al. reported elevated levels of adiponectin in pre-pubertal children with type 1 diabetes (27). The study by Morales et al. revealed that adiponectin levels in children and adolescents with type 1 diabetes did not differ from those in healthy subjects (26). Remarkably, in the present study, adiponectin levels at the time of diagnosis of diabetes were not different from adiponectin levels in control subjects but increased significantly during the follow-up period of the study. Diabetes duration in the two paediatric studies by Celi and Morales varied from 0.6 to 15.9 years and from 0.1 to 10 years respectively $(26,27)$. Duration of diabetes in studies conducted in adults was considerably longer (e.g. mean diabetes duration $27 \pm 8$ years (12)). According to our results, children do not have elevated adiponectin levels at the onset of diabetes but elevated adiponectin levels are detected after more than 0.5 years of diabetes duration. In the study by Morales, children with a diabetes duration of only 0.1 years were included; therefore, a certain percentage of the study subjects may well have low normal adiponectin concentrations.

This longitudinal study aimed to get more detailed information about determinants and influencing factors of adiponectin levels and longitudinal changes of adiponectin concentrations in children and adolescents. No significant difference in adiponectin concentrations regarding gender was seen. This observation is confirmed by the paediatric studies where gender differences were not seen either $(26,27)$. In contrast, the published studies in adults report on higher levels of adiponectin in women $(12,23-25)$. However, the findings in this study regarding the differences between adiponectin levels in males and females during pubertal development suggest an influence of gender. In healthy children and adolescents, adiponectin levels decreased significantly during puberty in boys compared with girls and at the end of puberty adiponectin levels are significantly lower in males than in females (30). In children and adolescents with type 1 diabetes, adiponectin concentrations also decline during puberty in males but are not different from adiponectin levels in females at the end of puberty. The reason for this observation remains unclear, suggesting other factors being involved in the regulation of adiponectin secretion 
over the course of the disease. Most studies in adults comprised subjects with a considerably longer diabetes duration and a great variance of age at onset of diabetes. The studies included patients with onset of type 1 diabetes during their first, second or third age decade and therefore at any age before, in or after puberty. Regulation of adiponectin may be different if diabetes is present during pubertal development or if onset of type 1 diabetes occurs after puberty. The effect of puberty could have further potential implications. Adiponectin may play an important role in the contribution of prepubertal years of type 1 diabetes on the development of diabetic complications. There are many controversies about the contribution of pre-pubertal years regarding microvascular complications. Some studies demonstrated that pre-pubertal diabetes duration contributed less to the development of diabetic complications (31-35). In addition, gender differences in the prevalence of atherosclerosis in type 1 diabetes could possibly be explained by the observed findings during puberty. Contrary to the healthy population, incidence rates and mortality of coronary heart disease (CHD) in women with type 1 diabetes are equal or even higher than in men $(36,37)$. In type 1 diabetes, coronary artery calcification is greatly increased and the gender difference in calcification is lost (38). The cardioprotective gender effect in healthy women is not present any longer in type 1 diabetes $(36,37)$. The reasons for the greater impact of $\mathrm{CHD}$ in women with type 1 diabetes are not clear and little of this gender effect can be explained by known risk factors.

The correlations of adiponectin concentrations and serum lipids, especially HDL, in females may further support this gender effect. The observation regarding lipids in this study is consistent with published studies in adults and children (39-41). A study of 839 healthy children reported gender-different associations between adiponectin levels and lipid profiles. Girls showed steeper declines in HDL and adiponectin with increasing BMI compared to boys, suggesting a complex age- and sex-related regulation of adiponectin secretion or clearance (40). Our study also confirmed different associations in boys and girls and implied a gender-related regulation of adiponectin levels. Probably because of the small number of subjects in the other age groups, significant correlations were mainly observed in the age group 11-14 years. Hormonal changes during puberty may also contribute to greater changes in lipid profile. Finally, the blood samples of this study were collected under nonfasting conditions. Whereas, this fact appears to have only a negligible impact on the level of adiponectin (45), an association between triglyceride and adiponectin concentrations cannot be evaluated leading to an incomplete picture of the lipid-adiponectin relationship in our patients.

The causes of elevated adiponectin levels in type 1 diabetes are not yet understood. Whether adiponectin is involved in the pathogenesis of complications in type 1 diabetes is still unclear. So far, the results of studies are conflicting and several theories exist. The Pittsburgh Epidemiology of Complications Study, a prospective follow-up study, showed that adiponectin levels inversely predicted the incidence of CHD in type 1 diabetes (25). Adiponectin could prove a marker for cardiovascular disease in type 1 diabetes. Therefore, another aim of this study was to evaluate predictors of adiponectin levels. This study is the only one examining adiponectin levels in children longitudinally over a period of time. The strongest predictor of adiponectin levels in the children and adolescents with type 1 diabetes at the end of the study was adiponectin level at baseline. This may be an indicator that adiponectin levels are partly or probably mainly genetically determined and therefore remain relatively constant (12). However, genetic studies were conducted in patients with insulin resistance or type 2 diabetes and no data are available on any relationship between adiponectin polymorphisms and type 1 diabetes (42-44).

Some limitations of the present study should be pointed out. First, the subgroup of children and adolescents with new onset type 1 diabetes comprises a wide age span, different pubertal stages and more males than females. It will be necessary to evaluate serum adiponectin levels at onset of type 1 diabetes and after a defined period of time in a considerably larger prospective study in order to confirm the observed result. Secondly, because adiponectin levels were measured yearly in our study, we are unable to discriminate how soon after insulin replacement adiponectin serum concentrations start to rise. In future, it will be important to evaluate the changes of adiponectin levels within the first year after onset of diabetes in a prospective study.

In summary, our study demonstrated that adiponectin levels are indeed higher in children and adolescents with no present cardiovascular disease. Adiponectin concentrations correlated with BMI but showed no association with metabolic control, confirming the results of studies in adults with type 1 diabetes. Furthermore, we revealed that adiponectin levels in type 1 diabetes during puberty are different compared to age- and pubertal stage-matched healthy controls, suggesting gender-dependent regulation of adiponectin levels in type 1 diabetes.

\section{Acknowledgements}

This publication contains work performed by Nicole Noack for the fulfilment of her MD thesis at the University of Leipzig, Germany. We thank the nurses and diabetes educators Annett Mauer and Kristin Claus for their valuable assistance and their parts in data collection and Sandy Laue and Annette Drechsler for their expert technical assistance. 


\section{Funding}

The study was supported by the German Diabetes Foundation ('Das Zuckerkranke Kind').

\section{References}

1 Chandran M, Phillips SA, Ciaraldi T \& Henry RR. Adiponectin: more than just another fat cell hormone? Diabetes Care 200326 2442-2450.

2 Kumada M, Kihara S, Sumitsuji S, Kawamoto T, Matsumoto S, Ouchi N, Arita Y, Akamoto Y, Shimomura I, Hiraoka H, Nakamura T, Funahashi T \& Matsuzawa Y. Association of hypoadiponectemia with coronary artery disease in men. Arteriosclerosis, Thrombosis and Vascular Biology 200323 85-89.

3 Fasshauer M, Paschke R \& Stumvoll M. Adiponectin, obesity and cardiovascular disease. Biochimie 200486 779-784.

4 Shimada K, Miyazaki T \& Daida H. Adiponectin and atherosclerosis disease. Clinica Chimica Acta 2004344 1-12.

5 Lau DCW, Dhillo B, Yan H, Szmitko PE \& Verma S. Adipokines: molecular links between obesity and atherosclerosis. American Journal of Physiology $2005 \mathbf{2 8 8}$ H2031-H2041.

6 Matsuzawa Y. Funahashi T. Kihara S \& Shimomura I. Adiponectin and metabolic syndrome. Arteriosclerosis, Thrombosis and Vascular Biology 200424 29-33.

7 Koerner A, Kratzsch J \& Kiess W. Adipocytokines: leptin - the classical, resistin - the controversical, adiponectin - the promising, and more to come. Best Practice and Research. Clinical Endocrinology and Metabolism 200519 525-546.

8 Matsuzawa Y. The metabolic syndrome and adipocytokines. FEBS Letters $2006 \mathbf{5 8 0} 2917-2921$.

9 Hu E, Liang P \& Spiegelman BM. AdipoQ is a novel adipose-specific gene dysregulated in obesity. Journal of Biological Chemistry 1996 271 10697-10703.

10 Weyer C, Funahashi T, Tanaka S, Hotta K, Matsuzawa Y, Pratley RE \& Tataranni PA. Hypoadiponectinemia in obesity and type 2 diabetes: close association with insulin resistance and hyperinsulinemia. Journal of Clinical Endocrinology and Metabolism 200186 1930-1935.

11 Higashiura K, Ura N, Ohata J, Togashi N, Takagi S, Saitoh S, Murakami H, Takagawa Y \& Shimamoto K. Correlations of adiponectin levels with insulin resistance and atherosclerosis in Japanese male populations. Clinical Endocrinology 200461 753-759.

12 Frystyk J, Tarnow L, Krarup Hansen T, Parving HH \& Flyvbjerg A. Increased serum adiponectin levels in type 1 diabetic patients with microvascular complications. Diabetologia 200548 1911-1918.

13 Ouchi N, Kihara S, Arita Y, Maeda K, Kuriyama H, Okamoto Y, Hotta K, Nishida M, Takahashi M, Nakamura H, Yamashita S, Funahashi T \& Matsuzawa Y. Novel modulator for endothelial adhesion molecules: adipocyte-deived plasma protein adiponectin. Circulation 1999100 2473-2476.

14 Pischon T, Girman CJ, Hotamisligil GS, Rifai N, Hu FB \& Rimm EB. Plasma adiponectin levels and risk of myocardial infarction in men. JAMA 2004291 1730-1737.

15 Arita Y, Kihara S, Ouchi N, Maeda K, Kuriyama H, Okamoto Y, Kumada M, Hotta K, Nishida M, Takahashi M, Nakamura T, Shimomura I, Muraguchi M, Ohmoto Y, Funahashi T \& Matsuzawa Y. Adipocyte-derived plasma protein adiponectin acts as a platelet-derived growth factor-BB-binding protein and regulates growth factor-induced common. Circulation $2002 \mathbf{1 0 5}$ 2893-2898.

16 Kubota N, Terauchi Y, Yamauchi T, Kubota T, Moroi M, Matsui J, Eto K, Yamashita T, Kamon J, Satoh H, Yano W, Froguel P, Nagai R, Kimura S, Kadowaki T \& Noda T. Disruption of adiponectin causes insulin resistance and neointimal formation. Journal of Biological Chemistry 2002277 25863-25866.
17 Okamoto Y, Kihara S, Ouchi N, Nishida M, Arita Y, Kumada M, Ohashi K, Sakai N, Shimomura I, Kobayashi H, Terasaka N, Inaba T, Funahashi $\mathrm{T} \&$ Matsuzawa $\mathrm{Y}$. Adiponectin reduces atherosclerosis in apolipoprotein E-deficient mice. Circulation $20021062767-2770$.

18 Matsuda M, Shimomura I, Sata M, Arita Y, Nishida M, Maeda N, Kumada M, Okamoto Y, Nagaretani H, Nishizawa H, Kishida K, Komuro R, Ouchi N, Kihara S, Nagai R, Funahashi T \& Matsuzawa Y. Role of adiponectin in preventing vascular stenosis. The missing link of adipo-vascular axis. Journal of Biological Chemistry 2002277 37487-37491.

19 Yamauchi T, Kamon J. Waki H, Imai Y, Shimozawa N, Hioki K, Uchida S, Ito Y, Takakuwa K, Matsui J, Takata M, Eto K, Terauchi Y, Komeda K, Tsunoda M, Murakami K, Ohnishi Y, Naitoh T, Yamamura K, Ueyama Y, Froguel P, Kimura S, Nagai R \& Kadowaki T. Globular adiponectin protected ob/ob mice from diabetes and ApoE-deficient mice from atherosclerosis. Journal of Biological Chemistry 2003278 2461-2468.

20 Laing SP, Swerdlow AJ, Slater SD, Botha JL, Burden AC, Waugh NR, Smith AW, Hill RD, Bingley PJ, Patterson CC, Qiao Z \& Keen H. The British Diabetic Association Cohort Study, II: causespecific mortality in patients with insulin-treated diabetes mellitus. Diabetic Medicine 199916 466-471.

21 Laing SP, Swerdlow AJ, Slater SD, Burden AC, Morris A, Waugh NR, Gatling W, Bingley PJ \& Patterson CC. Mortality from heart disease in a cohort of 23,000 patients with insulintreated diabetes. Diabetologia $2003 \mathbf{4 6} 760-765$.

22 Skrivarhaug T, Bangstad HJ, Stene LC, Sandvik L, Hanssen KF \& Joner G. Long-term mortality in a nationwide cohort of childhoodonset type 1 diabetic patients in Norway. Diabetologia 200649 298-305.

23 Hadjadj S, Aubert R, Fumeron F, Pean F, Tichet J, Roussel R, Marre M, SURGENE Study Group, \& DESIR Study Group, Increased plasma adiponectin concentrations are associated with microangiopathy in type 1 diabetic subjects. Diabetologia $2005 \mathbf{4 8}$ 1088-1092.

24 Saraheimo M, Forsblom C, Fagerudd J, Teppo AM, PetterssonFernholm K, Frystyk J, Flyvbjerg A, Groop PH \& FinnDiane study group, . Serum adiponectin is increased in type 1 diabetic patients with nephropathy. Diabetes Care 200528 1410-1414.

25 Costacou T, Zgibor JC, Evans RW, Otvos J, Lopes-Virella MF, Tracy RP \& Orchard TJ. The prospective association between adiponectin and coronary artery disease among individuals with type 1 diabetes. The Pittsburgh Epidemiology of Diabetes Complications Study. Diabetologia 200548 41-48.

26 Morales A, Wasserfall C, Brusko T, Carter C, Schatz D, Silverstein J, Ellis T \& Atkinson M. Adiponectin and leptin concentrations may aid in discriminating disease forms in children and adolescents with type 1 and type 2 diabetes. Diabetes Care 200427 2010-2014.

27 Celi F, Bini V, Papi F, Santilli E, Castellani MS, Ferretti A, Mencacci M, Berioli MG, De Giorgi G \& Falorni A. Circulating adipocytokines in non-diabetic and Type 1 diabetic children: relationship to insulin therapy, glycaemic control and pubertal development. Diabetic Medicine 200623 660-665.

28 Kromeyer-Hauschild K, Wabitsch M, Geller F, Ziegler A, Geiß HC Hesse V, von Hippel A, Jäger U, Johnsen D, Kiess W, Korte W, Kunze D, Menner K, Müller M, Niemann-Pilatus A, Remer T, Schäfer T, Wittchen HU, Zabransky S, Zellner K \& Hebebrand J. Perzentile für den body mass index für das kindes- und Jugendalter unter Heranziehung verschiedener deutscher Stichproben. Monatsschr Kinderheilkd $2001 \mathbf{1 4 9} 807-818$.

29 Reich A, Muller G, Gelbrich G, Deutscher K, Godicke R \& Kiess W. Obesity and blood pressure-results from the examination of 2365 schoolchildren in Germany. International Journal of Obesity and Related Metabolic Disorders 200327 1459-1464.

30 Bottner A, Kratzsch J, Muller G, Kapellen TM, Bluher S, Keller E, Bluher M \& Kiess W. Gender differences of adiponectin levels develop during the progression of puberty and are related to serum androgen levels. Journal of Clinical Endocrinology and Metabolism $2004894053-4061$ 
31 Donaghue KC, Fairchild JM, Craig ME, Chan AK, Hing S, Cutler LR, Howard NJ \& Silink M. Do all prepubertal years of diabetes duration contribute equally to diabetes complications? Diabetes Care 200326 1224-1229.

32 Olsen BS, Sjolie AK, Hougaard P, Johannesen J, Marinelli K, Jacobsen BB, Mortensen HB \& Danish Study Group of Diabetes in Childhood, . The significance of the prepubertal diabetes duration for the development of retinopathy and nephropathy in patients with type 1 diabetes. Journal of Diabetes and its Complications 2004 18 160-164.

33 Svensson M, Nystrom L, Schon S \& Dahlquist G. Age at onset of childhood-onset type 1 diabetes and the development of end-stage renal disease: a nationwide population-based study. Diabetes Care $200629538-542$.

34 Svensson M, Eriksson JW \& Dahlquist G. Early glycemic control, age at onset, and development of microvascular complications in childhood-onset type 1 diabetes: a population-based study in northern Sweden. Diabetes Care 200427 955-962.

35 Danne T, Kordonouri O, Hovener G \& Weber B. Diabetic angiopathy in children. Diabetic Medicine $1997141012-1025$.

36 Laing SP, Swerdlow AJ, Slater SD, Burden AC, Morris A, Waugh NR, Gatling W, Bingley PJ \& Patterson CC. Mortality from heart disease in a cohort of 23000 patients with insulintreated diabetes. Diabetologia 200346 760-765.

37 Soedamah-Muthu SS, Chaturvedi N, Toeller M, Ferriss B, Reboldi P, Michel G, Manes C, Fuller JH; EURODIAB Prospective Complications Study Group. Risk factors for coronary heart disease in type 1 diabetic patients in Europe: the EURODIAB Prospective Complications Study. Diabetes Care 200427 530-537.

38 Colhoun HM, Rubens MB, Underwood SR \& Fuller JH. The effect of type 1 diabetes mellitus on the gender difference in coronary artery calcification. Journal of the American College of Cardiology $2000362160-2167$.

39 Cnop M, Havel PJ, Utzschneider KM, Carr DB, Sinha MK, Boyko EJ, Retzlaff BM, Knoop RH, Brunzell JD \& Kahn SE. Relationship of adiponectin to body fat distribution, insulin sensitivity and plasma lipoproteins: evidence for independent roles of age and sex. Diabetologia $2003 \mathbf{4 6} 459-469$.
40 Baratta R, Amato S, Degano C, Farina MG, Patané G, Vigneri R \& Frittitta L. Adiponectin relationship with lipid metabolism is independent of body fat mass. evidence from both cross-sectional and intervention studies. Journal of Clinical Endocrinology and Metabolism 200489 2665-2671.

41 Ong KK, Frystyk J, Flyvbjerg A, Petry CJ, Ness A \& Dunger DB. Sexdiscordant associations with adiponectin levels and lipid profiles in children. Diabetes 200655 1337-1341.

42 Fumeron F, Aubert R, Siddiq A, Betoulle D, Pean F, Hadjadj S, Tichet J, Wilpart E, Chesnier MC, Balkau B, Froguel P, Marre M; Epidemiologic Data on the Insulin Resistance Syndrome (DESIR) Study Group. Adiponectin gene polymorphisms and adiponectin levels are independently associated with the development of hyperglycemia during a 3-year period: the epidemiologic data on the insulin resistance syndrome prospective study. Diabetes 2004 53 1150-1157.

43 Stefan N, Machicao F, Staiger H, Machann J, Schick F, Tschritter O, Spieth C, Weigert C, Fritsche A, Stumvoll M \& Haring HU. Polymorphisms in the gene encoding adiponectin receptor 1 are associated with insulin resistance and high liver fat. Diabetologia $2005482282-2291$.

44 Siitonen N, Pulkkinen L, Mager U, Lindstrom J, Eriksson JG, Valle TT, Hamalainen H, Ilanne-Parikka P, KeinanenKiukaanniemi S, Tuomilehto J, Laakso M \& Uusitupa M. Association of sequence variations in the gene encoding adiponectin receptor 1 (ADIPOR1) with body size and insulin levels. The Finnish Diabetes Prevention Study. Diabetologia 2006 49 1795-1805.

45 Shand B, Elder P, Scott R, Frampton C \& Willis J. Biovariability of plasma adiponectin. Clinical Chemistry and Laboratory Medicine $2006441264-1268$.

Received 15 April 2007

Accepted 17 July 2007 